\title{
In vivo effect of innate immune response modulating impurities (IIRMIs) on the skin milieu using a macaque model: Impact on product immunogenicity
}

\author{
Lydia A Haile, Montserrat Puig, Swamy Kumar Polumuri, Jill Ascher, Daniela Verthelyi
}

Laboratory of Immunology, Division of Biotechnology Review and Research III, Office of Biotechnology Products, Center for Drug Evaluation and Research, Food and Drug Administration, Silver Spring, Maryland, United States of America

\begin{abstract}
Unwanted immune responses to therapeutic proteins can severely impact their safety and efficacy. Studies show that the presence of trace amounts of host cell and process-related impurities that stimulate pattern recognition receptors (PRR) can cause local inflammation and enhance product immunogenicity. Here we used purified PRR agonists (PRRAgs) as model impurities to assess the minimal level of individual innate immune response modulating impurities (IIRMIs) that could activate a local immune response. We show that levels of endotoxin as low as 10pg (0.01 EU), 1 ng for Poly I:C, 100ng for FSL-1, CLO75 or muramyl dipeptide, $1 \mu \mathrm{g}$ for Flagellin or $\beta$-glucan, or $5 \mu \mathrm{g}$ for CpG ODN increased expression of genes linked to innate immune activation and inflammatory processes in skin of Rhesus macaques. Furthermore, spiking studies using rasburicase as a model therapeutic, showed that the levels of PRRAgs that induced detectable gene up-regulation in the skin were associated with increased immunogenicity for rasburicase. This study underscores the need for testing for multiple IIRMIs in biologics, strengthening the connection between the local mRNA induction in skin, innate immune activation, and antibody development in primates, and provides an indication of the levels of IIRMI in therapeutic products that could impact on product immunogenicity.
\end{abstract}




\section{Introduction}

Immune responses to therapeutic products are frequent and can significantly affect their safety and efficacy ${ }^{1,2}$. The consequences of these are exemplified by the episodes of pure red cell aplasia that followed the development of antibodies to Eprex®, or the reduced therapeutic efficacy subsequent to the development of antibodies to $\alpha$ glucosidase, IFN $\beta$ or coagulation factor VIII ${ }^{3,4}$. Although all proteins, self and foreign, bear antigenic sites to which an immune response can theoretically be directed, the actual development of an immune response is thought to depend on numerous productrelated (homology to self, post-translational modifications, presence of aggregates), and patient-related (e.g. age, treatment regimen, immune status) factors ${ }^{5,6}$. Understanding and controlling the factors that promote immunogenicity to therapeutic products is critical to obtaining safe and effective products and may reduce the need for extensive clinical trials to assess immunogenicity ${ }^{7}$. One of the elements that may increase the risk of immunogenicity of a product is the presence of host cell derived and process-related impurities that can stimulate innate immune receptors in the host, acting as adjuvants.

Biotechnology products, whether they are recombinant or naturally derived, are manufactured using complex expression and production systems that usually involve genetically modified bacteria, yeast, insect or mammalian cells and fermentation media 5,8 . Downstream purification processes are designed to eliminate impurities such as residual host DNA, host cell proteins, and endotoxins, however trace levels of these may co-purify with the product. For example, although parenteral products are sterile, they may have detectable bioburden until the latest stages of drug substance manufacturing ${ }^{9}$. As a result, trace amounts of host cell or process derived impurities could be deposited together with the product in the tissue and foster an inflammatory or immune response. The cells in the subcutaneous tissue and peripheral blood express a variety of surface pattern recognition receptors (PRR). Examples of PRRs include transmembrane Toll-like receptor (TLR) and C-type lectin receptor (CLR), as well as a variety of cytoplasmic receptors that bind nucleic acids or peptidoglycans (e.g. bacterial muramyl dipeptide) expressed on stromal (particularly in epithelial cells in skin and other barrier tissues) and immune cells (such as macrophages and dendritic cells) ${ }^{10}$. Each of 
these receptors is triggered by various highly conserved microbial structures (which we designate PRR agonists (PRRAgs)) including bacterial carbohydrates (such as lipopolysaccharide (LPS) and mannose), nucleic acids (DNA or RNA), bacterial peptides (flagellin, microtubule elongation factors), peptidoglycans and lipoteichoic acids, lipoproteins, fungal glucans and chitin ${ }^{11}$. In addition, these receptors are also activated by molecular patterns associated with cellular stress and tissue damage (e.g heat shock proteins or reactive oxygen species ${ }^{12}$. Activated PRR trigger several intracellular signaling pathways leading to the production of pro-inflammatory cytokines (IL-6, TNF $\alpha$, IFNs) and chemokines (CXCL8/IL-8, CCL5, CXCL10) that attract granulocytes, as well as macrophages, dendritic cells, and other antigen presenting cells to the site, enhance their antigen-presenting capabilities, foster trafficking to the local lymph nodes and enable the initiation of an immune response ${ }^{13-16}$. When impurities can activate PRR we designate them as innate immune response modifying impurities (IIRMls).

The slow absorption, ease of self-administration and the development of auto-injectors have made the subcutaneous (SC) tissue the most popular parenteral route for biologics. This route has been associated with higher immunogenicity risk for some products and this could be linked to the innate immune system in the skin ${ }^{17}$. The major population of cells in the skin stroma: keratinocytes, fibroblasts and melanocytes, express a wide variety of PRRs ${ }^{18-20}$. For example, human keratinocytes express most TLR although some may be non-functional; melanocytes express TLR4; and fibroblasts express TLR3 and TLR4 ${ }^{14,21-24}$. Importantly, the skin and subcutaneous space are also populated with resident and trafficking immune cells including Langerhans cells (LCs), monocytes/macrophages, dendritic cells (DCs), innate lymphoid cells (ILCs), lymphocytes, and mast cells, each expressing an array of PRRs including toll like receptors (TLRs), dectin 1 and NOD like receptors that can initiate and instruct a local innate immune and inflammatory, as well as foster a systemic immune response ${ }^{19,20}$. Among the dendritic cells that infiltrate the skin and subcutaneous tissue TLRs 1, 2, 3, 4, 5, 6,8 and 10 are usually expressed in myeloid DCs (mDCs), Langerhans cells (LC) express TLR1, 2, 3, 5, 6, whereas plasmacytoid DCs (pDCs), which express TLRs 7 and 9 , do not reside in the skin but traffic to it upon stimulation,. Thus, for example, 
remnants of a bacterial cell wall may activate mDCs via TLR2 and TLR4 leading to the activation of NF-kB, whereas, nucleic acids may trigger TLRs 3 and 7 on mDC and pDC eliciting a downstream response mediated by IRF3 and IRF7 ${ }^{25}$. Currently there are readily available validated assays to detect a few impurities such as endotoxins and DNA and these are regularly monitored in biotechnology products, however other impurities that can act as adjuvants such as flagellin or $\beta$-glucans are seldom monitored. In previous studies our group and others have shown that very low levels of PRRAgs are sufficient to foster the secretion of cytokines and immunoglobulins in vitro, and that impurities may synergize in their adjuvant effect ${ }^{14,26-28}$. While IIRMI were shown to increase immunogenicity in mice, an understanding of the minimal amounts of these PRRAgs that could increase the immunogenicity risk of a product in humans is lacking. Since the in vitro response of non-human primates to IIRMI appears to be similar to that of humans, we have used non-human primates to gain some understanding of the levels of these impurities that can activate a local inflammatory or innate immune response in vivo.

Most of the studies in vivo assessing the factors involved in product immunogenicity have been conducted in mice. To assess the effect of IIRMI, the differences in the cellular distribution of PRRs and the architecture of the skin hinder the translation of the findings in mice to human ${ }^{29}$. Indeed, humans have 10 TLRs and 22 NLRs, whereas mice have 12 and 34 respectively ${ }^{30-33}$ and TLR8, which responds to ssRNA, in human and non-human primates is not functional in mice ${ }^{34}$. Preclinical studies are often conducted in non-human primates. Although there is some variation in PRR expression between Rhesus and humans, they exhibit a more comparable cellular distribution and expression pattern of TLRs on APCs and other cell types than mice, and more similar skin architecture to that of humans ${ }^{35}$. In addition, the response in vitro to TLR agonists appears to be conserved between humans and Rhesus macaques ${ }^{36,37}$. This makes them a good model for understanding the potential impact of IIRMI on product immunogenicity ${ }^{38,39}$. In this study, we used the macaque model to explore whether IIRMI can act as adjuvants, increasing the immunogenicity risk of therapeutic proteins administered subcutaneously (SC). We show that trace levels of PRRAgs can elicit detectable immune response in the skin of non-human primates marked by increased 
expression of mRNA for chemokines, cytokines and cell surface receptors linked to antigen presentation. This suggests that these PRRAgs could increase antigen uptake and presentation by local immune cells leading to enhanced $T$ and $B$ cell responses ${ }^{40}$. Lastly, we show that co-administration of a foreign protein with the levels of PRRAgs that induce a local response is associated with increased ADA levels to the protein in primates. This is important as several studies in human patients show that higher antibody titers are correlated with clinical impact ${ }^{41}$.

\section{Materials and Methods}

\section{Reagents}

Antigens binding pattern recognition receptors (PPRAgs): LPS from Salmonella Minnesota Re 595 was purchased from Calbiochem (Darmstadt, Germany), Poly(l:C), Flagellin, FSL-1, imiquimod, MDP and $\beta$-glucan were purchased from InvivoGen (San Diego, CA, USA). CpG ODN D35 (D-ODN; 5'-ggTGCATCGATGCAGGGGgg-3') was synthesized at the FDA core facility (Rockville, MD, USA) ${ }^{37}$. PRRAgs were used the concentration indicated in each individual figure. The purity of the individual IIRMI was confirmed using human embryonic kidney (HEK) 293 cell expressing individual PRR. Rasburicase (Elitek $\Theta$ ) is a recombinant urate-oxidase indicated for initial management of plasma uric acid levels in pediatric and adult patients with leukemia, lymphoma, and solid tumor malignancies who are receiving anti-cancer therapy expected to result in tumor lysis and subsequent elevation of plasma uric acid ${ }^{42}$.

\section{Animals}

Twenty-five male and female rhesus macaques (Macaca mulatta) were maintained at the FDA White Oak animal facility. All experiments were approved by the White Oak Consolidated Animal Care and Use Committee (WOC ACUC), and conducted in accordance with recommendations put forth in the Guide for the Care and Use of Laboratory Animals, eighth edition. Macaques were housed in approved facilities and 
monitored daily by veterinary staff. Non-human primates groups were weight-and gender matched ( $\mathrm{n}=4-5 /$ group).

For the subcutaneous injection, animals were anesthetized with ketamine $(5-10 \mathrm{mg} / \mathrm{kg})$ prior to the inoculation so that they were safely immobilized. Skin biopsies were taken 6 hours later under ketamine $(5-10 \mathrm{mg} / \mathrm{kg})$ and xylazine $(0.5-1 \mathrm{mg} / \mathrm{kg})$.

\section{TLR agonist treatment}

PRRAgs agonists were prepared in $50 \mu \mathrm{l}$ of sterile saline and injected SC using a 30 gauge needle in the shaved chest. Control macaques $(n=4-5)$ received $0.9 \%$ normal saline solution (Quality Biological, Gaithersburg, MD, USA). All inoculations were done in the chest under the assumption that the local cellular architecture and skin microbiome would be similar allowing for comparison across biopsies. Inoculations were performed in alternate sides of the chest, at least 4 inches apart and at least 2 weeks apart in order to minimize the effect of each biopsy on the following response to IIRMI.

\section{Rhesus tissue sample collection and homogenization}

Skin biopsies $4 \mathrm{~mm}$ in diameter were obtained from the site of injection under aseptic conditions 6 hours post-injection of PRRAgs using a biopsy punch (Miltex, York, PA, USA). Hemostasis was achieved using sterile gauze and digital pressure. The skin incision was closed with Vetbond (3M) surgical glue. The tissues were immediately submerged in TRIzol reagent (Invitrogen, Carlsbad, CA, USA), and stored at $-80^{\circ} \mathrm{C}$ until processing.

To homogenize the tissues, skin biopsies were thawed and mixed with one millimeterdiameter Zirconia Beads (Biospec Products, Bartlesville, OK, USA). The samples were shredded by glass-bead friction using the Precellys 24, Cryolys system (Bertin Technologies, France) using the following settings: 6800rpm; number of runs 2; run time 
30s; pause time 30s. Homogenates were transferred into sterile 2-mL eppendorf tubes and total RNA was isolated as described below.

Blood from Rhesus macaques anesthetized with $10-15 \mathrm{mg} / \mathrm{kg}$ ketamine was collected via femoral venipuncture in BD Vacutainer ACD Solution A tubes (Becton Dickinson, Franklin Lakes, NJ). Red blood cells were lysed with ACK lysis buffer (Gibco) following the manufacturer's instruction and the cells were washed three times with cold PBS and the pellet was resuspended with TRIzol and frozen at $-80 \mathrm{C}$ until further preparation. Serum was obtained from blood collected in serum separation (tiger-top tubes; Covidien, Mansfield, MA) and was stored at $-80 \mathrm{C}$.

\section{Nucleic acid isolation and qRT-PCR analysis}

Total RNA was freshly isolated from skin biopsy homogenate or whole blood lysate using Trizol (Carlsbad, CA, USA) as per manufacturer recommendations. For CpGinjected monkey skin samples and their saline controls, mRNA was further purified by MicroPoly(A) Purist columns (Ambion, Austin, TX, USA). One microgram of total RNA or $0.5 \mu \mathrm{g}$ mRNA was treated with DNAse by using Turbo DNA-free Kit (Ambion, Austin, TX, USA) and subsequently reverse transcribed using High Capacity cDNA RT Kit (Applied Biosystems, Foster City, CA, USA), as per manufacturer's instructions. Custom-made Rhesus specific TaqMan® Micro Fluidic Cards containing panels of 48 gene expression assays were loaded with a sample volume of cDNA solution equivalent to $125 \mathrm{ng}$ of the original RNA, mixed with 2x Universal Master Mix (Applied Biosystems). Real time PCR assays were conducted in a Taqman $7900 \mathrm{HT}$ or a Viia7 (ABI) instrument with the following thermocycling conditions: $94^{\circ} \mathrm{C}$ for $10 \mathrm{~min}$ followed by 40 cycles of amplification at $94^{\circ} \mathrm{C}$ for $30 \mathrm{sec}$ and $60^{\circ} \mathrm{C}$ for $1 \mathrm{~min}$. Delta delta Ct calculations were based on normalization with housekeeping gene (18S or GAPDH) expression values. The mRNA expression of inflammatory cytokines IL-6 and IL-8 was quantified by qPCR with individual gene expression assays (Applied Biosystems) and its fold increase was calculated relative to the values obtained from biopsies following the 
saline injection of the same macaque. The impact of the inoculation with saline on gene expression induction was negligible as determined by comparison with biopsies from untreated macaques. Increases in mRNA expression greater than 2.5 were considered as positive.

\section{Rasburicase treatment in Rhesus macaques}

Rhesus macaques were injected SC with rasburiciase $(0.02 \mathrm{mg} / \mathrm{kg})$ alone or together with increasing amount of endotoxin or flagellin on day 1,15 and 30. Serum samples were taken at base line day $0,1,15,30$ and 60 . The serum level of anti-rasburicase antibodies was quantified by ELISA and expressed as fold increase over the levels obtained prior to treatment with the drug.

\section{ELISA for anti-rasburicase antibodies}

96 well plates were coated with $100 \mu \mathrm{L}$ of antigen (rasburicase) to final concentration of $20 \mu \mathrm{g} / \mathrm{mL}$ in carbonate buffer $(\mathrm{pH} 9.6)$ and incubated over night at $4^{\circ} \mathrm{C}$. Plates were blocked with $2 \%$ BSA for $2 \mathrm{~h}$. After washing, serum samples (diluted 1:40) or goat-antiuricase antibody $(27 \mu \mathrm{g} / \mathrm{mL}$ to $7.8 \mathrm{ng} / \mathrm{mL})$ was incubated overnight at $4^{\circ} \mathrm{C}$. The detection of captured antibodies was performed with protein $A / G$ labeled with Alkaline Phosphatase and absorbance was measured using FilterMax F3 multimode microplate reader (Molecular Devices, Sunnyvale, CA, USA). Differences in anti-rasburicase antibodies were analyzed using the PROC MIXED analysis with repeated measures procedure in $\mathrm{SAS} \otimes$ version 9.4 . 


\section{Result}

\section{Trace levels of IIRMIs induce a complex pattern of gene expression in the skin}

Multiple studies assessing vaccine adjuvants for cancer or infections have shown that inclusion of PRRAgs can trigger innate immune responses in skin and increase the immunogenicity of a co-administered antigen ${ }^{43,44}$. More recently, we have shown that mice can respond to very low levels of PRRAgs in vitro and proposed that even trace levels of IIRMI could increase the risk of product immunogenicity ${ }^{27}$. To understand the effect of inoculating trace levels of impurities that can activate innate immune receptors into the subcutaneous space in humans we used Rhesus macaques as a model. In Rhesus macaques, as in humans, the skin shows transcripts for TLR2, TLR4, TLR5, TLR6 as well as TLR 9 even in the absence of stimulation (Supplementary Figure 1) and can respond to TLR agonists ${ }^{45}$. To explore whether trace levels of PRRAgs modify the immune milieu of the subcutaneous space, groups of 3-5 Rhesus macaques were inoculated with low levels of purified PRRAgs SC followed by full depth skin biopsies at the site 6 hours later. Macaques received inoculations with agonists of TLR 4

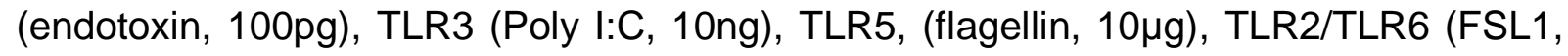

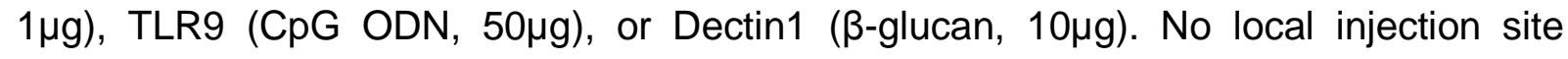
reactions were evident. Six hours post-inoculation the site was biopsied and the mRNA collected was tested for gene expression using a panel of 48 immune related genes. Since we observed that the inoculation of saline into the SC space was sufficient to induce some expression of genes linked to inflammation (data not shown), we used the gene expression evident in biopsies obtained from each individual macaque 6 hours after the inoculation with sterile saline as the comparator for all our studies as described in Materials and Methods. As shown in Figure 1, all of the PRRAgs induced the upregulation of selected immune/inflammation-related gene expression at the site of inoculation. Interestingly, while each of them elicited a distinct pattern of gene expression in the skin, we observed some common genes induced by all the different PRRAgs tested. These included increased transcripts for neutrophil-related chemokine IL-8 and alarmins S100A8 and S100A9. In addition, IL-6, IL-1ß, CCL2, and CXCL10, were evident following injection of endotoxin, Polyl:C, Flagellin, FSL-1 and CpG-ODN 
but not $\beta$-glucan. These responses suggest that the inoculation of low levels of PRRAgs in the subcutaneous space induces innate immune and inflammatory responses that could lead to an influx and activation of immune cells. The increase in CD80/CD86 suggests that there is an influx and/or activation of resident antigen presenting cells (APC) that could augment the uptake and presentation of a co-administered antigen. The responses induced however were not necessarily similar, as Poly $(\mathrm{I}: \mathrm{C})$ and CpGODN induced higher mRNA levels of IRF7, MX-1 consistent with locally increased levels of IFNs. Inoculation of CpG-ODN also increased transcripts for IL-10, PRF1, prostaglandin-endoperoxide synthase 2 (PTGS2/COX2), neutrophil cytosolic factor 2 (NCF2), as well as genes expressed by APC such as CD209/ICAM-3, CD40 and CD14. In contrast, animals that received $\beta$-glucan showed increased expression of NF- $\mathrm{KB}$, CD69, CD80 and CD86 suggestive of increased presence of activated antigen presenting cells at the site, but no increase in IL1 $\alpha$, IL-1 $1 \beta$, IL6, or IFN $\gamma$. These studies indicated that different PRRAgs induce distinct responses in the skin, however it was not clear whether the difference in the pattern of gene expression corresponded to distinct activation paths or could be attributed to the differences in PRRAg concentrations used for the different receptors. To address whether the difference in gene activation pattern was linked to the levels of PRRAg delivered we performed a dose response study, wherein groups of 5 macaques were inoculated SC with three different levels of FSL1 or CpG ODN and biopsies were collected 6 hours post inoculation. As shown in Figure 2, at these very low levels, gene expression is dose dependent, but the subset of genes induced by both TLR agonists were different, with FSL-1 inducing downregulation of CD94, Perforin1, and ICOS and upregulating the expression of CD209 (also known as DC-SIGN) and IL-1 $\beta$ that could suggest activation of dendritic cells and mobilization of lymphocytes, while CpG ODN induced stronger upregulation of CXCL10, IRF7 and MX1 indicative of type I interferon induction. Together, these studies showed that low levels of PRRAGs activate the local innate immune system. 
Determination of the lowest levels of PRRAgs that induce innate immune activation in the skin and subcutaneous tissue

We reasoned that it was important to delineate the lowest levels of PRRAgs that induced local immune activation and therefore may be capable of increasing the immunogenicity risk of a product. To address this question we used the expression of IL-8 as a biomarker since all of the PRRAgs tested induced its expression. Groups of 5 macaques were inoculated with different levels of endotoxin, poly I:C, flagellin, FSL-1, CpG ODN and $\beta$-glucan as well as TLR7/8 agonist CL075 and NOD2 agonist MDP until the lowest PRRAg concentration to elicit a response in at least 2 of 5 macaques was identified (Supplementary Figure 2). Inoculations were performed at least 2 weeks apart to avoid any residual effect (after 2 weeks all gene expression had returned to baseline, data not shown). As shown in Figure 3, injection of 10pg of TLR4-ligand endotoxin resulted in the induction of IL-8 gene expression in the skin of 2 out of 5 macaques. A similar increase in transcript levels was evident in macaques inoculated with 1 ng of MDP, 10ng of FSL-1, or CL075. Relatively higher levels were required for

inducing $\mathrm{IL}-8$ expression in macaques treated with flagellin $(1 \mu \mathrm{g})$, $\beta$-glucan $(1 \mu \mathrm{g})$, or Poly I:C (1ng) as well as CpG ODN $(5 \mu \mathrm{g})$. This shows that low amounts of different microbial components are capable of activating a local response, but the concentration of PRRAgs needed to activate the skin's immune system are distinct for each agonist. Not surprisingly, when we tested peripheral blood for signs of systemic innate immune activation, the levels of PRRAgs that induced a local detectable immune response in skin were lower than those needed to elicit increased gene expression in the blood (Supplementary Figure 3) suggesting that monitoring gene expression in peripheral blood for changes in immune-related gene induction may not reflect the activation at the site of inoculation even if the amounts of IIRMI are sufficient to augment the antibody response to a protein. 


\section{IIRMIs differentially activate innate immune response pathways in skin}

Activation of PRRs leads to recruitment of adaptor molecules and activation of different downstream signaling pathways that result in distinct patterns of gene expression ${ }^{46}$. We reasoned that while the minimal dose of TLR ligands that induce NF- $\kappa B$ translocation to the nucleus can be readily determined by monitoring the expression of mRNA for IL-6 and IL-8, for IIRMIs that induce other activation paths, such as IRF3 or IFR7, different readouts may be more sensitive. For example, PRRAgs that activate the IRF7 pathway leading to the production of type I interferons (IFN) may be better monitored by assessing the expression of IFN-inducible genes. Thus, to determine the lowest levels of TLR3 and 9 agonists, we monitored the gene expression of IFNa8, CD80, CXCL10, MX-1 and IRF7. Interestingly, increased levels of mRNA for ISGs MX-1, CD80, CXCL10, and IRF7 were evident following injection of TLR3 agonist Poly I:C at lower doses $(1 \mathrm{ng})$ than those needed to elicit IL-6 or IL-8 $(1 \mu \mathrm{g})$. In contrast, at least $5 \mu \mathrm{g}$ of TLR9 agonist CpG-ODN were required to detect 3-fold or higher increase in $\mathrm{MX}-1$, IFNa8, IRF7 or CXCL10 expression (Figure 4A-E) indicating that some PRR may be more sensitive to the presence of impurities in the subcutaneous space than others.

\section{Trace level of IIRMIs can synergize to enhance expression of pro-inflammatory mediators on the skin.}

PRR ligands, whether derived from the host cells or remnants of adventitious agents, are likely to be complex and trigger multiple PRR on different cells. In a previous study we had shown that LPS and CpG-ODN synergized to increase the immune response of mouse splenocytes and that synergic immune activation was associated with increased immunogenicity in vivo in mice ${ }^{27}$. Therefore we next explored whether the observed expression profile of immune related genes induced by a single impurity changed when multiple PRRAgs were co-inoculated into the skin milieu. Macaques were injected with low levels of endotoxin, Polyl:C, CpG-ODN or $\beta$-glucan alone or in combination. The pattern of gene expression induced by the individual PRRAgs were compared to the ones obtained after co-adminsitration of two different model IIRMI (endotoxin and CpGODN, endotoxin and Polyl:C and endotoxin and $\beta$-glucan. Fold-increases in gene expression were calculated as the increase in mRNA levels over the response to saline 
in the skin biopsies of the same macaque. As shown on Figure 5A-B, the skin of macaques that received endotoxin as well as Poly(l:C) or CpG ODN showed a marked increase in mRNA expression for chemokines (CXCL10), APC related co-stimulatory molecules (CD40, CD80, CD69) and cytokines (IL-6, IL-1 $\beta$ ) 6 hours post inoculation, suggesting an increase in NF-KB mediated immune activation. Similarly, the skin tissue in macaques injected with the two IIRMIs showed higher levels of ISGs IRF7 and MX-1 transcripts compared to those stimulated with either endotoxin, Poly(I:C), or CpG-ODN alone. Of note, not all combination of PRRAgs tested resulted in synergistic increase in the expression of genes linked to inflammation at 6 hours, as a marginal or no increase was observed in macaques that receive endotoxin plus $\beta$-glucan (Figure 5C). Indeed, the pattern of gene expression resembled that of endotoxin alone suggesting that the response to the endotoxin dominates the response overriding the response elicited by the $\beta$-glucan (Figure $\mathbf{5 C}$ ). This shows that impurities that activate multiple PRR may induce different gene expression patterns depending on the combination of receptors triggered. This should be considered when assessing the immunogenicity risk posed by the different impurities.

\section{Augmentation of immunogenicity of therapeutic protein by IIRMIs in non-human primates}

As shown above, the amount of model IIRMI that trigger the local expression of genes linked to inflammation in skin is lower than the one that activates gene expression in peripheral blood. To determine whether the low levels of local inflammation were sufficient to enhance the immunogenicity of a therapeutic protein, Rhesus macaques were injected subcutaneously with Rasburiciase alone or together with increasing amount of endotoxin and flagellin on days 1,15 and 30. Urate-oxidase is a foreign protein in primates and the Rasburicase label indicates that this is a product that is immunogenic inducing ADA in over $60 \%$ of the patients in clinical studies ${ }^{47}$. This product was chosen as a model foreign therapeutic protein because to determine whether trace amounts PRRAgs could accelerate or augment the antibody response in macaques. The levels of antibodies to rasburicase in sera were compared at base line, days 15, 30, 45, and 60. As shown in Figure 6, Rhesus macaques that received 
rasburicase together with 100pg and 10ng of endotoxin or rasburicase with $10 \mu \mathrm{g}$ of flagellin, developed higher levels of ADA by day 60 than those that received rasburicase lone. This indicates that the levels of PRRAgs that induce a detectable increase in local inflammatory response are sufficient to enhance the risk of product immunogenicity.

\section{Discussion}

Innate immune PRRAgs have been shown to act as effective adjuvants in the context of vaccines $^{48}$. In previous studies our group and others showed that trace amounts of PRRAgs can activate the innate immune system increasing the immunogenicity risk of therapeutic proteins ${ }^{27}$. This led us to propose that the presence of IIRMIs should be investigated beyond the presence of endotoxin and nucleic acids, as part of the assessment of immunogenicity risk following changes in manufacturing or raw material 27,49. Complete elimination of IIRMI may not be possible for some biologics, so understanding the levels of PRRAgs that could effectively foster an immune response is essential to determine how sensitive the methods used to detect IIRMI need to be in order to control the clinically relevant levels of IIRMI. This cannot be done using murine models since it is known that their immune cells are less sensitive to PRRAgs than those of human. Here we show that the introduction of trace levels of individual purified model PRRAgs into the subcutaneous space in Rhesus macaques leads to local innate immune activation. We further show that PRRAgs that induce a detectable response in inflammatory gene expression in skin can act as adjuvants to a coadministered therapeutic protein increasing their immunogenicity. Not surprisingly the mass of the individual PRRAgs needed to trigger gene transcription varied widely among individual PRRAgs as 10pg of endotoxin induced an increase in IL-8 transcript whereas higher levels were required for FSL-1 or $\beta$-glucan/flagellin. The response to each PRRAg was dose dependent, but even at trace levels the IIRMls triggered the transcription of multiple genes in our array.

Since different model IIRMls trigger distinct receptors and pathways, the array of genes induced depended on the specific PRRAg. For example, PRRAgs that activated the 
IRF3/IRF7 pathway induced the transcription of interferon inducible genes such as MX1 and IRF7 at lower concentrations than were needed to induce NF-KB-mediated IL-6 responses. Conversely, the lowest levels $\beta$-glucan induced an increase in NF-KB transcripts and associated genes linked with APC maturation but not with inflammation. As a consequence, the most sensitive "reporter readout genes" vary depending on the receptor triggered. Despite this, it was possible to identify genes such as IL-8, S100A8 and S100A9 that were triggered by all model IIRMls inoculated into the subcutaneous space suggesting they could be useful in detecting unknown IIRMI in products.

While it is possible to obtain skin biopsies of Rhesus macaques to assess local innate immune activation during the course of preclinical studies, measuring innate immune activation in peripheral blood would not only more practical, but would indicate whether the immune stimulating effect is systemic. As shown in supplementary Figure 3, following a SC inoculation of PRRAgs, the levels of PRRags that induced a detectable increase in gene expression in peripheral blood were higher than those needed to achieve a local inflammatory response or to induce increased antibody production. This suggests that monitoring innate immune activation in peripheral blood may not be as sensitive when determining whether impurities in a product administered SC could increase the risk of product immunogenicity. Future studies will need to focus on identifying sensitive clinically relevant biomarkers of innate immune activation in peripheral blood.

The use of Rhesus macaques as opposed to mice to investigate the effect of IIRMI on local immune activation and product immunogenicity has advantages and disadvantages. In previous studies, it was shown that peripheral blood mononuclear cells (PBMC) from Rhesus macaques and human PBMC had a similar response to CpG-ODN and other PRR agonists in vitro ${ }^{37,50}$ and in vivo ${ }^{45}$. However, Rhesus macaques are outbred and therefore expected to vary in their response to the inoculation of IIRMIs. Additionally, the low number of animals that can be tested and the limited sampling points from each animal hinders detailed exploration. With only 5 animals per group, our study used the arbitrary cut point of the detection of increased gene expression in at least 2 of 5 animals to identify the lowest PRRAg concentrations that induced a detectable response. Importantly, this should not be construed as 
indicating that $40 \%$ of the subjects developing detectable responses in their skin, but only as a proof of concept that very low PRRAgs concentrations that do not necessarily induce detectable systemic responses are able to induce immune activation in vivo. In addition, since the local gene expression was assessed at single time point, the sampling time may not have been optimal for all the genes tested, so the list of genes induced is not meant to be comprehensive. Lastly, the aim of the study was to determine the minimal levels of IIRMI that could enhance the immune response to a therapeutic protein in rhesus macaques. Therefore the model that was used, rasburicase, was that of a protein that would easily induce an immune response. The levels of IIRMI that could facilitate a break in tolerance to a therapeutic protein may be higher and would largely depend on the degree of preexisting tolerance to the protein.

Recombinant and naturally derived therapeutic proteins and peptides can contain multiple impurities, including variants of the product, and those derived from raw material and the manufacturing process. The innate immune system has multiple receptors that can sense the presence of these impurities. The family of PRR has grown exponentially over the last 15 years and new receptors continue to be identified that recognize different microbial components ${ }^{51-54}$. Some of the PRRs are promiscuous in that they can be triggered by multiple stimuli ${ }^{46}$. For example, TLR4 can be activated by endotoxin from gram negative bacteria, heat shock protein 60, fibrinogen and the Env protein from murine moloney leukemia virus, as well as by endogenous ligands (beta defensins, Mrp8 and Mrp14, biglycan, hyaluronan and HMGB1) ${ }^{55}$. In contrast, some are highly specific, such as DNA bearing CpG motifs stimulating TLR9, or 5'triphosphorylated dsRNA activating RIG-I (retinoic acid-inducible gene 1). In addition, the same impurity can be recognized by multiple receptors likely resulting in distinct responses. For example $\beta$-glucans from fungi and bacteria can be detected by Dectin1, Complement receptor 3 , lactosylceramide, and scavenger receptors ${ }^{56}$. Of note, our studies interrogated only a fraction of possible PRRAgs and did not consider possible interactions between the local effect of the PRRAgs and the therapeutic protein of interest (or active pharmacological ingredient) as these exceeded the aims of the study. Future studies may need to address these interactions. Currently there are a number of screening techniques that can be used to assess drug products for the presence of 
impurities; however this remains challenging particularly for complex carbohydrate and protein products. The most frequently used test for endotoxin is the Limulus Amoebocyte Lysate (LAL). LAL is fast and sensitive but tests exclusively for endotoxin 57. Furthermore, endotoxin recovery with the LAL depends on the type of endotoxin present, the presence of other PRRAgs, and the protein concentration in the products 58. The rabbit pyrogen test (RPT) and Macrophage activation tests (MAT) can detect both endotoxin as well as non-endotoxin components of bacteria that induce a pyrogenic response ${ }^{57,59}$. However the RPT is expensive and requires extensive use of animals, while the MAT requires the availability of primary human cells, which poses technical and safety challenges that have been discussed extensively ${ }^{60}$. Even more importantly, RPT readout is based on pyrogenicity and not immune activation or potential adjuvant effect. Lastly recently our group proposed 2 different types of cell linebased assays that could be used to assess products for the presence of IIRMI based on their ability to induce cytokine responses in vitro ${ }^{49}$. Although these cell line-based assays that monitor PRR activation are sufficient for detecting the concentrations of most immunomodulatory IIRMI, they failed to detect certain PRRAgs (e.g. Poly I:C and MDP) that activate the local innate immune system in vivo ${ }^{49}$. This suggests that better testing systems are needed to detect a wide array of possible IIRMI. We expect that understanding the levels of IIRMI that induce innate immune activation in vivo will aide in development of new and better assays to characterize IIRMI in biologics.

\section{Acknowledgements}

The assertions herein are the private ones from the authors and are not to be construed as official or as reflecting the views of the Food and Drug Administration. We thank Lewis Shankle, and the personnel of the animal facility for care of the macaques.. We thank Dr. Amy Rosenberg and Dr Susan Kirshner for helpful discussions and careful review of the manuscript.

This study was supported in part by a Senior Postgraduate Research Fellowship Award to D.I. from the Oak Ridge Institute for Science and Education (ORISE) through an 
interagency agreement between the U.S. Department of Energy and the U.S. Food and Drug Administration. The authors acknowledge CDER Critical Path funding for this research project.

\section{Figure Legend}

Figure 1. Different IIRMIs induce distinct patterns of innate immune associated gene expression in the skin and subcutaneous tissue

Six groups of Rhesus macaques ( $n=3-4$ animals/group) received a subcutaneous

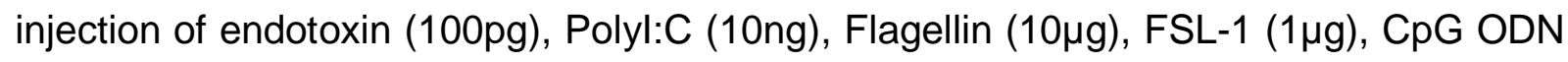
(D35 50 $\mu$ g) or $\beta$-glucan $(10 \mu g)$ in the chest under anesthesia. Six hours later the site was biopsied as described in Materials and Methods. The skin was homogenized, mRNA was collected and gene expression changes were assessed using a custom designed 48 gene TLDA. For each macaque the expression levels were expressed as fold changes over the expression in skin following an inoculation with saline.

Figure 2. Local gene expression following SC inoculation of PRRAgs is dose dependent

Two groups of Rhesus macaques ( $n=3-4$ animals/group) received 3 doses of increasing concentrations of FSL-1 or CpG ODN subcutaneously at 2 week intervals as described in materials and methods. The inoculation sites were biopsied 6 hours after each inoculation to collect mRNA. The skin was homogenized, mRNA was collected and gene expression changes were assessed using a custom designed 48 gene TLDA. For each macaque the expression levels were expressed as fold changes over the expression in skin following an inoculation with saline.

Figure 3. Identification of the lowest level of PRRAgs that induces a local increase in the expression of IL-8 
Rhesus macaques ( $\mathrm{n}=5 /$ group) were injected subcutaneously with model PRRAgs (A) Endotoxin, (B) MDP, (C) FSL-1, (D) CLO75, (E) Flagellin, (F) $\beta$-glucan, (G) Polyl:C, or (H) CpG-ODN. After 6 hours a skin biopsy was obtained at the site, mRNA extracted as described, and IL-8 mRNA levels measured by qRT-PCR. Expression levels are indicated as fold increases over the values obtained from biopsies obtained from the same macaque 6 hours after receiving an inoculation with a similar volume of saline. Increases in expression above 2.5 fold are considered positive (Broken black line).

Figure 4. Expression of interferon inducible genes as readouts for PRRAgs. Rhesus macaques $(n=5)$ were injected with indicated levels of CpG-ODN (A-E) and Polyl:C (F-J) subcutaneously. The level of mRNA for MX1, IFN 88 , CD80, IRF7, and CXCL10 were determined in the local skin 6 hours after post injection by qRT-PCR. Expression levels are indicated as fold increases over the values obtained from biopsies obtained from the same macaque 6 hours after receiving an inoculation with a similar volume of saline.

Figure 5. PRRAgs synergize to activate APC related genes on the skin. Rhesus macaques were injected with (A) Endotoxin (100pg), Polyl:C (10ng), or a combination of

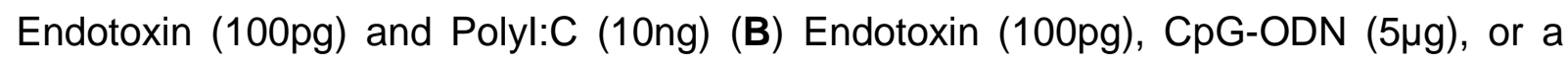

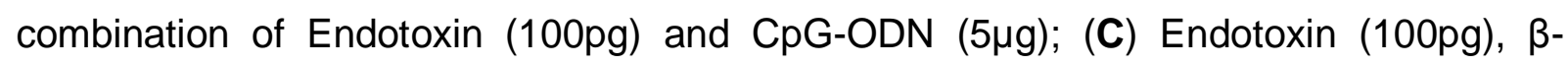
glucan $(1 \mu \mathrm{g})$, or a combination of Endotoxin (100pg) and $\beta$-glucan $(1 \mu \mathrm{g})$. Skin biopsies were collected from the at the injection site after 6 hours. Gene expression changes were assessed using a TLDA array consisting of 48 innate immune related genes. Gene expression levels are expressed as fold changes over saline for individual macaques and graphed using GraphPad Prism.

Figure 6. Levels of PRRAgs that induce a detectable response at the inoculation site increase protein immunogenicity. Rhesus macaques $(n=5)$ were injected with rasburiciase alone or together with increasing amount of endotoxin or flagellin on days 1,15 and 30 and 60. Serum samples were taken at base line D0, 15, 30, 45 and 60. 
Anti-rasburicase antibodies were quantified by ELISA and results are expressed as optical densities at $405 \mathrm{~nm}$ for each individual macaque.

Supplementary Figure 1. Different TLRs are expressed on the skin of Rhesus macaques. Base line mRNA expression of TLR2, 4, 5, 6 and 9 were quantified by qPCR from $4 \mathrm{~mm}$ skin biopsy from the untreated Rhesus macaques $(n=10)$. Data is presented in relation to $18 \mathrm{~S}$ as $2-\mathrm{dCt} \times 10^{7}$ and depicted in log scale as mean $\pm \mathrm{SEM}$.

Supplementary Figure 2. Experimental design for study to identify the lowest level of PRRag to induce detectable innate immune activation in vivo. For all animals skin biopsies were obtained on week 1 prior to any inoculations in order to establish baseline mRNA expression in skin for individual animals. Two weeks after the initial biopsy all monkeys received $50 \mu \mathrm{L}$ saline subcutaneously on week 2 to establish gene expression changes attributable to the stress of SC inoculation. On week 4, Rhesus macaques $(n=5)$ were divided in to groups and injected subcutaneously with model PRRAgs (A) Endotoxin, (B) MDP (C) FSL-1 (D) CLO75 (E), Flagellin , (F) $\beta$ glucan (G) Polyl:C (H) CpG-ODN. In an effort to relate the signal obtained in vitro and in vivo with PRRAgs, the dose of the first inoculation was based on the concentration of PRRAgs that induced an IL- 6 and IL- 8 gene expression increase in human PBMC in vitro. Subsequent doses were escalated or de-escalated (10X per time point) until the lowest PRRAg concentration to elicit a response in at least 2 of 5 macaques was identified. All inoculations were performed at least 2 weeks apart and on alternating sides of the thoracic area to minimize the risk of residual effects for a total of 4 week intervals between inoculations in the same area. Indeed, no evidence of gene activation at the site of inoculation was observed in biopsies carried out 2 weeks after inoculation. No inoculations were performed less than 2 inches apart.

Supplementary Figure 3. Immunomodulatory levels of PRRAgs inoculated into the subcutaneous space elicit systemic signal. Rhesus macaques $(n=5)$ were injected with indicated levels of $(\mathbf{A})$ Endotoxin, or (B) Flagellin subcutaneously. Blood 
and skin biopsy were collected 6 hours post injection. The levels of mRNA for IL-8 mRNA were determined in skin and whole blood lysate 6 hours after post injection. The fold increases were calculated relative to the values obtained from biopsies following the saline injection of the same macaque. Note that levels of endotoxin and flagellin that augment the antibody response do not elicit increased IL-8 (or IL-6, not shown) expression in peripheral blood.

\section{References}

1. Rosenberg AS 2003. Immunogenicity of biological therapeutics: a hierarchy of concerns. Dev Biol (Basel) 112:15-21.

2. Schellekens $\mathrm{H}$ 2002. Immunogenicity of therapeutic proteins: clinical implications and future prospects. Clin Ther 24(11):1720-1740; discussion 1719.

3. Kishnani PS, Goldenberg PC, DeArmey SL, Heller J, Benjamin D, Young S, Bali D, Smith SA, Li JS, Mandel H, Koeberl D, Rosenberg A, Chen YT 2010. Cross-reactive immunologic material status affects treatment outcomes in Pompe disease infants. Molecular genetics and metabolism 99(1):26-33.

4. Rosenberg AS, Verthelyi D, Cherney BW 2012. Managing uncertainty: a perspective on risk pertaining to product quality attributes as they bear on immunogenicity of therapeutic proteins. J Pharm Sci 101(10):3560-3567. 
5. Schellekens $\mathrm{H}$ 2008. How to predict and prevent the immunogenicity of therapeutic proteins. Biotechnol Annu Rev 14:191-202.

6. Subramanyam M 2006. Immunogenicity of biotherapeutics-an overview. J Immunotoxicol 3(3):151-156.

7. Lee S, Raw A, Yu L, Lionberger R, Ya N, Verthelyi D, Rosenberg A, Kozlowski S, Webber K, Woodcock J 2013. Scientific considerations in the review and approval of generic enoxaparin in the United States. Nat Biotechnol 31(3):220-226.

8. Rosenberg AS, Worobec A 2004. A risk-based approach to immunogenicity concerns of therapeutic protein products Part 1 Considering consequences of the immune response to a protein. Biopharm Int 17(11):22-+.

9. Wang X, Hunter AK, Mozier NM 2009. Host cell proteins in biologics development: Identification, quantitation and risk assessment. Biotechnol Bioeng 103(3):446-458.

10. Medzhitov R 2001. Toll-like receptors and innate immunity. Nat Rev Immunol 1(2):135-145.

11. Kawai T, Akira S 2010. The role of pattern-recognition receptors in innate immunity: update on Toll-like receptors. Nat Immunol 11(5):373-384.

12. Muralidharan S, Mandrekar P 2013. Cellular stress response and innate immune signaling: integrating pathways in host defense and inflammation. J Leukoc Biol 94(6):1167-1184.

13. Gursel M, Verthelyi D, Klinman DM 2002. CpG oligodeoxynucleotides induce human monocytes to mature into functional dendritic cells. Eur J Immunol 32(9):2617-2622.

14. Kwissa M, Nakaya HI, Oluoch H, Pulendran B 2012. Distinct TLR adjuvants differentially stimulate systemic and local innate immune responses in nonhuman primates. Blood 119(9):2044-2055.

15. Steinhagen F, Kinjo T, Bode C, Klinman DM 2011. TLR-based immune adjuvants. Vaccine 29(17):3341-3355.

16. Verthelyi D, Kenney RT, Seder RA, Gam AA, Friedag B, Klinman DM 2002. CpG

oligodeoxynucleotides as vaccine adjuvants in primates. J Immunol 168(4):1659-1663.

17. Fathallah AM, Bankert RB, Balu-lyer SV 2013. Immunogenicity of subcutaneously administered therapeutic proteins--a mechanistic perspective. AAPS J 15(4):897-900.

18. Hari A, Flach TL, Shi Y, Mydlarski PR 2010. Toll-like receptors: role in dermatological disease. Mediators Inflamm 2010:437246.

19. Miller LS 2008. Toll-like receptors in skin. Adv Dermatol 24:71-87.

20. Nestle FO, Di Meglio P, Qin JZ, Nickoloff BJ 2009. Skin immune sentinels in health and disease. Nat Rev Immunol 9(10):679-691.

21. Kollisch G, Kalali BN, Voelcker V, Wallich R, Behrendt H, Ring J, Bauer S, Jakob T, Mempel M, Ollert M 2005. Various members of the Toll-like receptor family contribute to the innate immune response of human epidermal keratinocytes. Immunology 114(4):531-541.

22. Lebre MC, van der Aar AM, van Baarsen L, van Capel TM, Schuitemaker JH, Kapsenberg ML, de Jong EC 2007. Human keratinocytes express functional Toll-like receptor 3, 4, 5, and 9. J Invest Dermatol 127(2):331-341.

23. Mempel M, Voelcker V, Kollisch G, Plank C, Rad R, Gerhard M, Schnopp C, Fraunberger P, Walli AK, Ring J, Abeck D, Ollert M 2003. Toll-like receptor expression in human keratinocytes: nuclear factor kappaB controlled gene activation by Staphylococcus aureus is toll-like receptor 2 but not toll-like receptor 4 or platelet activating factor receptor dependent. J Invest Dermatol 121(6):1389-1396.

24. Terhorst D, Kalali BN, Ollert M, Ring J, Mempel M 2010. The role of toll-like receptors in host defenses and their relevance to dermatologic diseases. Am J Clin Dermatol 11(1):1-10.

25. Udey MC 2004. Skin dendritic cells in immunity and autoimmunity. J Investig Dermatol Symp Proc 9(1):15-17. 
26. Napolitani G, Rinaldi A, Bertoni F, Sallusto F, Lanzavecchia A 2005. Selected Toll-like receptor agonist combinations synergistically trigger a T helper type 1-polarizing program in dendritic cells. Nat Immunol 6(8):769-776.

27. Verthelyi D, Wang V 2010. Trace Levels of Innate Immune Response Modulating Impurities (IIRMIs) Synergize to Break Tolerance to Therapeutic Proteins. PLoS ONE 5(12):e15252.

28. Zaitseva M, Romantseva T, Blinova K, Beren J, Sirota L, Drane D, Golding H 2012. Use of human MonoMac6 cells for development of in vitro assay predictive of adjuvant safety in vivo. Vaccine 30(32):4859-4865.

29. Sun J, Li N, Oh KS, Dutta B, Vayttaden SJ, Lin B, Ebert TS, De Nardo D, Davis J, Bagirzadeh R, Lounsbury NW, Pasare C, Latz E, Hornung V, Fraser ID 2016. Comprehensive RNAi-based screening of human and mouse TLR pathways identifies species-specific preferences in signaling protein use. Sci Signal 9(409):ra3.

30. Geddes K, Magalhaes JG, Girardin SE 2009. Unleashing the therapeutic potential of NOD-like receptors. Nat Rev Drug Discov 8(6):465-479.

31. Hornung V, Rothenfusser S, Britsch S, Krug A, Jahrsdorfer B, Giese T, Endres S, Hartmann G 2002. Quantitative expression of toll-like receptor 1-10 mRNA in cellular subsets of human peripheral blood mononuclear cells and sensitivity to CpG oligodeoxynucleotides. J Immunol 168(9):4531-4537.

32. Takeda K, Akira S 2015. Toll-like receptors. Curr Protoc Immunol 109:14 12 11-10.

33. Yin Q, Fu TM, Li J, Wu H 2015. Structural biology of innate immunity. Annu Rev Immunol 33:393-416.

34. Cervantes JL, Weinerman B, Basole C, Salazar JC 2012. TLR8: the forgotten relative revindicated. Cell Mol Immunol 9(6):434-438.

35. Ketloy C, Engering A, Srichairatanakul U, Limsalakpetch A, Yongvanitchit K, Pichyangkul S, Ruxrungtham $\mathrm{K}$ 2008. Expression and function of Toll-like receptors on dendritic cells and other antigen presenting cells from non-human primates. Vet Immunol Immunopathol 125(1-2):18-30.

36. Klinman DM, Verthelyi D, Takeshita F, Ishii KJ 1999. Immune recognition of foreign DNA: a cure for bioterrorism? Immunity 11(2):123-129.

37. Verthelyi D, Ishii KJ, Gursel M, Takeshita F, Klinman DM 2001. Human peripheral blood cells differentially recognize and respond to two distinct CPG motifs. J Immunol 166(4):2372-2377.

38. Gujer C, Sundling C, Seder RA, Karlsson Hedestam GB, Lore K 2011. Human and rhesus plasmacytoid dendritic cell and B-cell responses to Toll-like receptor stimulation. Immunology 134(3):257-269.

39. Verthelyi D 2006. Adjuvant properties of CpG oligonucleotides in primates. Methods Mol Med 127:139-158.

40. Iwasaki A, Medzhitov R 2015. Control of adaptive immunity by the innate immune system. Nat Immunol 16(4):343-353.

41. Grossberg SE, Oger J, Grossberg LD, Gehchan A, Klein JP 2011. Frequency and Magnitude of Interferon $\beta$ Neutralizing Antibodies in the Evaluation of Interferon $\beta$ Immunogenicity in Patients with Multiple Sclerosis. Journal of Interferon \& Cytokine Research 31(3):337-344.

42. Rodriguez M, Campara M, Haaf C 2011. Rasburicase in cancer-related hyperuricemia. Drugs Today (Barc) 47(8):591-603.

43. Barry M, Cooper C 2007. Review of hepatitis B surface antigen-1018 ISS adjuvant-containing vaccine safety and efficacy. Expert Opin Biol Ther 7(11):1731-1737.

44. Garcon N, Morel S, Didierlaurent A, Descamps D, Wettendorff M, Van Mechelen M 2011. Development of an ASO4-adjuvanted HPV vaccine with the adjuvant system approach. BioDrugs 25(4):217-226. 
45. Puig M, Tosh KW, Schramm LM, Grajkowska LT, Kirschman KD, Tami C, Beren J, Rabin RL, Verthelyi D 2012. TLR9 and TLR7 agonists mediate distinct type I IFN responses in humans and nonhuman primates in vitro and in vivo. J Leukoc Biol 91(1):147-158.

46. Brubaker SW, Bonham KS, Zanoni I, Kagan JC 2015. Innate immune pattern recognition: a cell biological perspective. Annu Rev Immunol 33:257-290.

47. Allen KC, Champlain AH, Cotliar JA, Belknap SM, West DP, Mehta J, Trifilio SM 2015. Risk of anaphylaxis with repeated courses of rasburicase: a Research on Adverse Drug Events and Reports (RADAR) project. Drug Saf 38(2):183-187.

48. Kasturi SP, Skountzou I, Albrecht RA, Koutsonanos D, Hua T, Nakaya HI, Ravindran R, Stewart S, Alam M, Kwissa M, Villinger F, Murthy N, Steel J, Jacob J, Hogan RJ, Garcia-Sastre A, Compans R, Pulendran B 2011. Programming the magnitude and persistence of antibody responses with innate immunity. Nature 470(7335):543-547.

49. Haile LA, Puig M, Kelley-Baker L, Verthelyi D 2015. Detection of innate immune response modulating impurities in therapeutic proteins. PLoS One 10(4):e0125078.

50. Barreiro LB, Marioni JC, Blekhman R, Stephens M, Gilad Y 2010. Functional comparison of innate immune signaling pathways in primates. PLoS Genet 6(12):e1001249.

51. Bhat N, Fitzgerald KA 2014. Recognition of cytosolic DNA by cGAS and other STING-dependent sensors. Eur J Immunol 44(3):634-640.

52. Iwasaki A, Medzhitov R 2010. Regulation of adaptive immunity by the innate immune system. Science 327(5963):291-295.

53. Moura-Alves P, Fae K, Houthuys E, Dorhoi A, Kreuchwig A, Furkert J, Barison N, Diehl A, Munder A, Constant P, Skrahina T, Guhlich-Bornhof U, Klemm M, Koehler AB, Bandermann S, Goosmann C, Mollenkopf HJ, Hurwitz R, Brinkmann V, Fillatreau S, Daffe M, Tummler B, Kolbe M, Oschkinat H, Krause $\mathrm{G}$, Kaufmann SH 2014. AhR sensing of bacterial pigments regulates antibacterial defence. Nature 512(7515):387-392.

54. Shi J, Zhao Y, Wang Y, Gao W, Ding J, Li P, Hu L, Shao F 2014. Inflammatory caspases are innate immune receptors for intracellular LPS. Nature 514(7521):187-192.

55. Piccinini AM, Midwood KS 2010. DAMPening inflammation by modulating TLR signalling. Mediators Inflamm 2010.

56. Akramiene D, Kondrotas A, Didziapetriene J, Kevelaitis E 2007. Effects of beta-glucans on the immune system. Medicina (Kaunas) 43(8):597-606.

57. Hasiwa N, Daneshian M, Bruegger P, Fennrich S, Hochadel A, Hoffmann S, Rivera-Mariani FE, Rockel C, Schindler S, Spreitzer I, Stoppelkamp S, Vysyaraju K, Hartung T 2013. Evidence for the detection of non-endotoxin pyrogens by the whole blood monocyte activation test. ALTEX 30(2):169208.

58. Buchacher A, Krause D, Wiry G, Weinberger J 2010. Elevated Endotoxin Levels in Human Intravenous Immunoglobulin Concentrates Caused by (1->3)-\{beta\}-D-Glucans. PDA J Pharm Sci Technol 64(6):536-544.

59. Fennrich S, Fischer M, Hartung T, Lexa P, Montag-Lessing T, Sonntag HG, Weigandt M, Wendel A 1999. Detection of endotoxins and other pyrogens using human whole blood. Dev Biol Stand 101:131139.

60. Wunderlich C, Schumacher S, Kietzmann M 2014. Pyrogen detection methods: comparison of bovine whole blood assay (bWBA) and monocyte activation test (MAT). BMC Pharmacol Toxicol 15:50. 


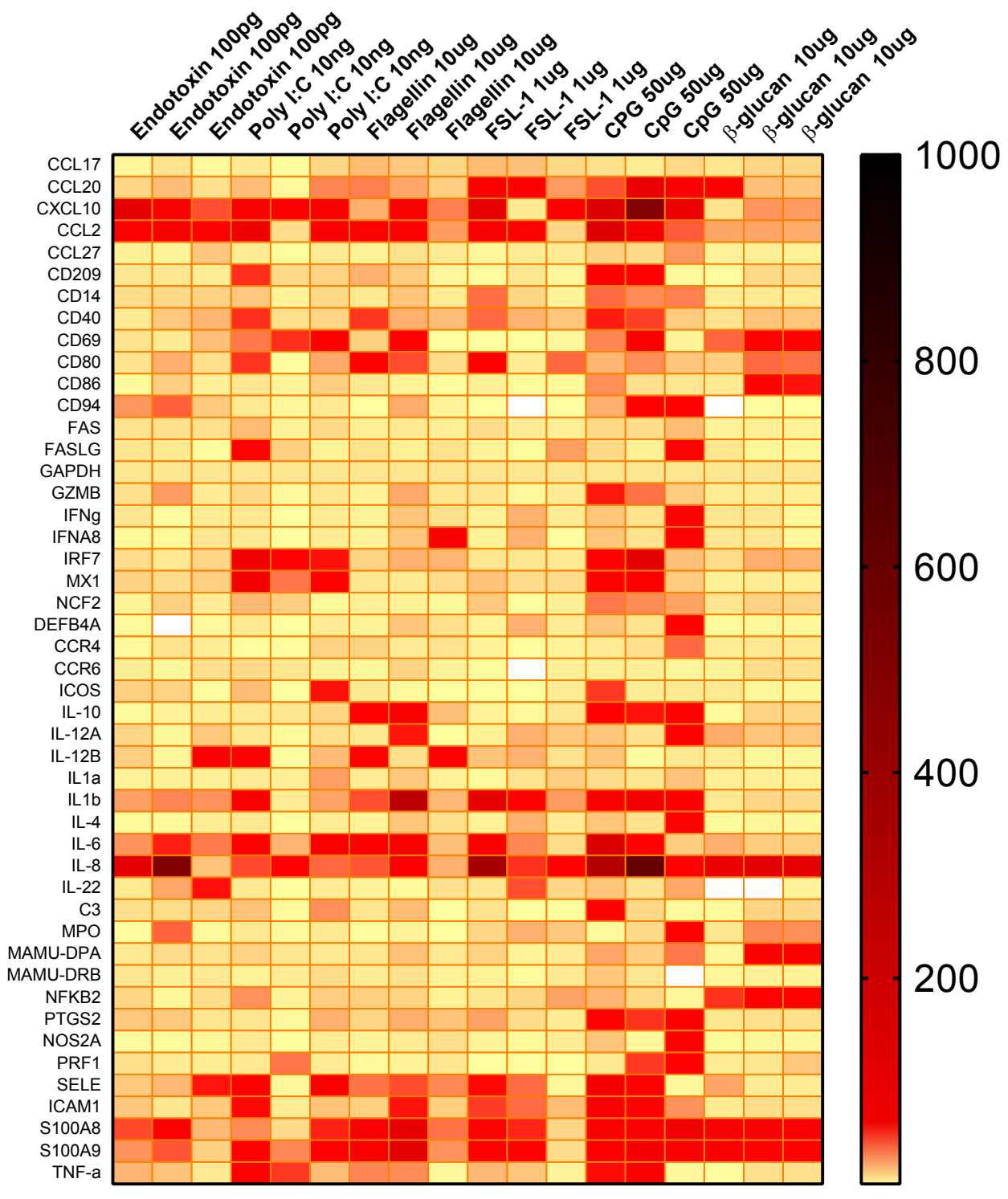

Figure 1 
A
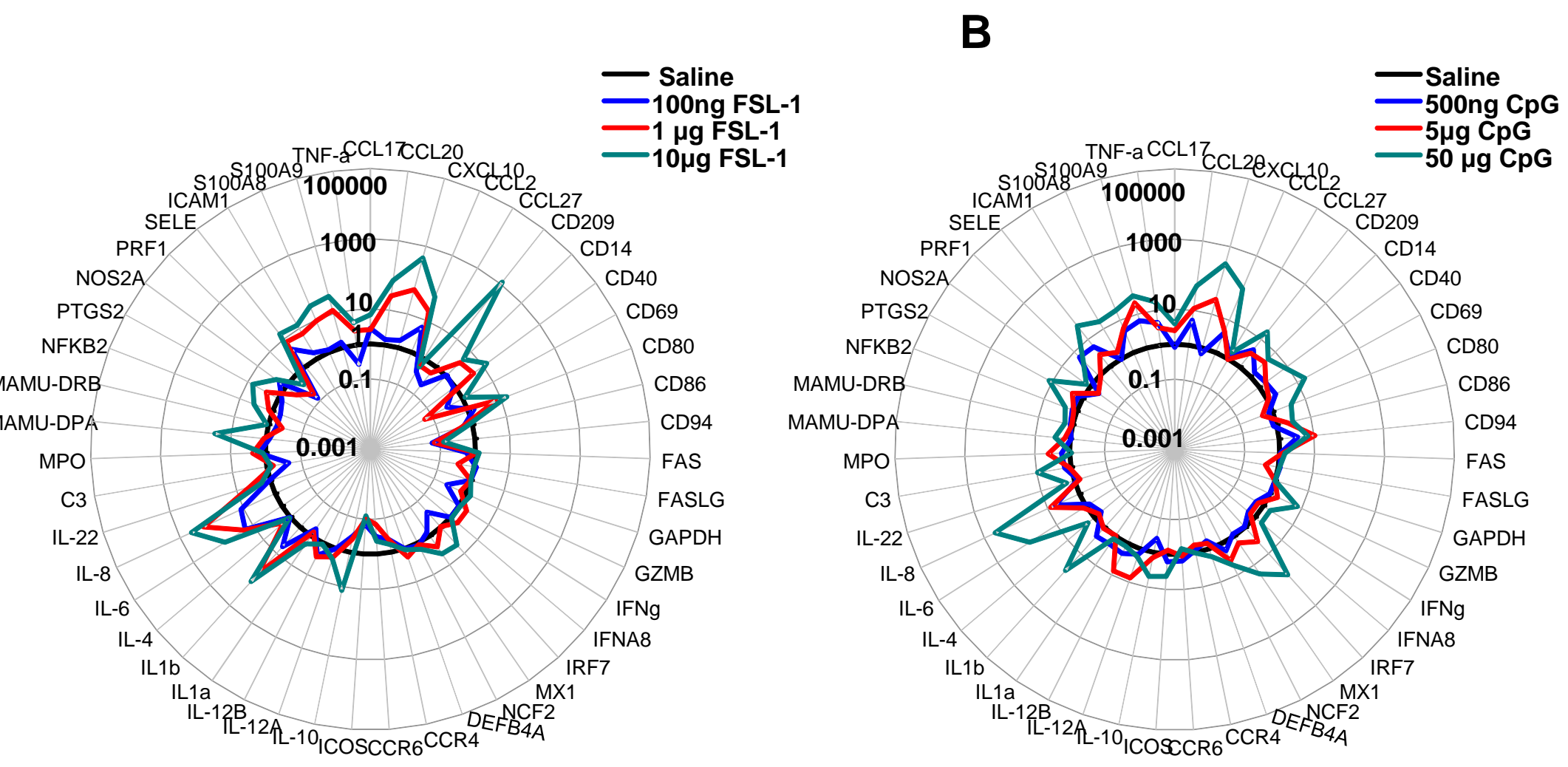

Figure 2 
A

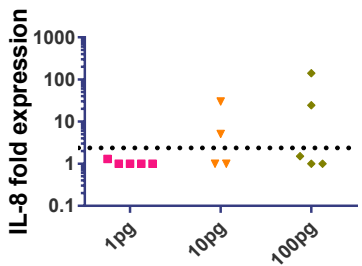

Endotoxin

B

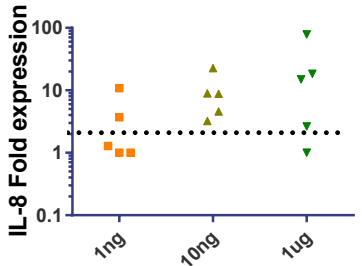

C

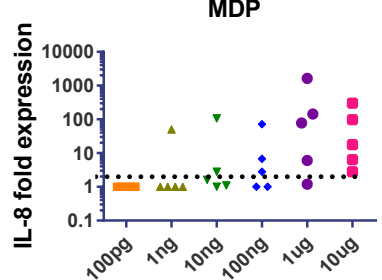

FSL-1

D

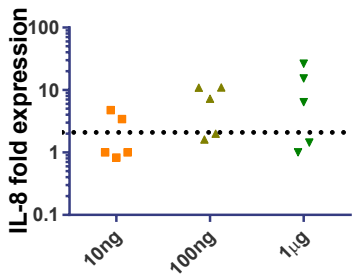

CLO75
E

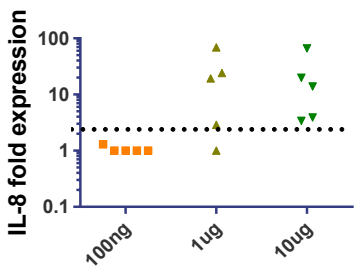

Flagellin

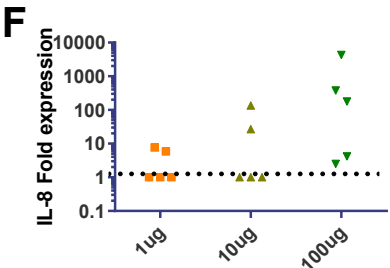

G

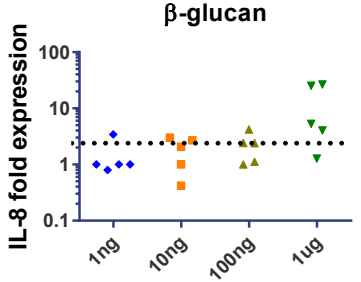

Polyl:C

H

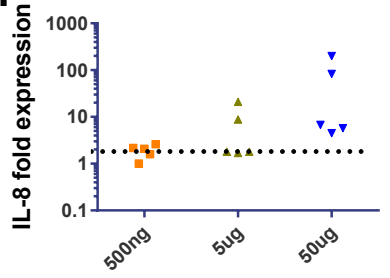

CPG-ODN D35 


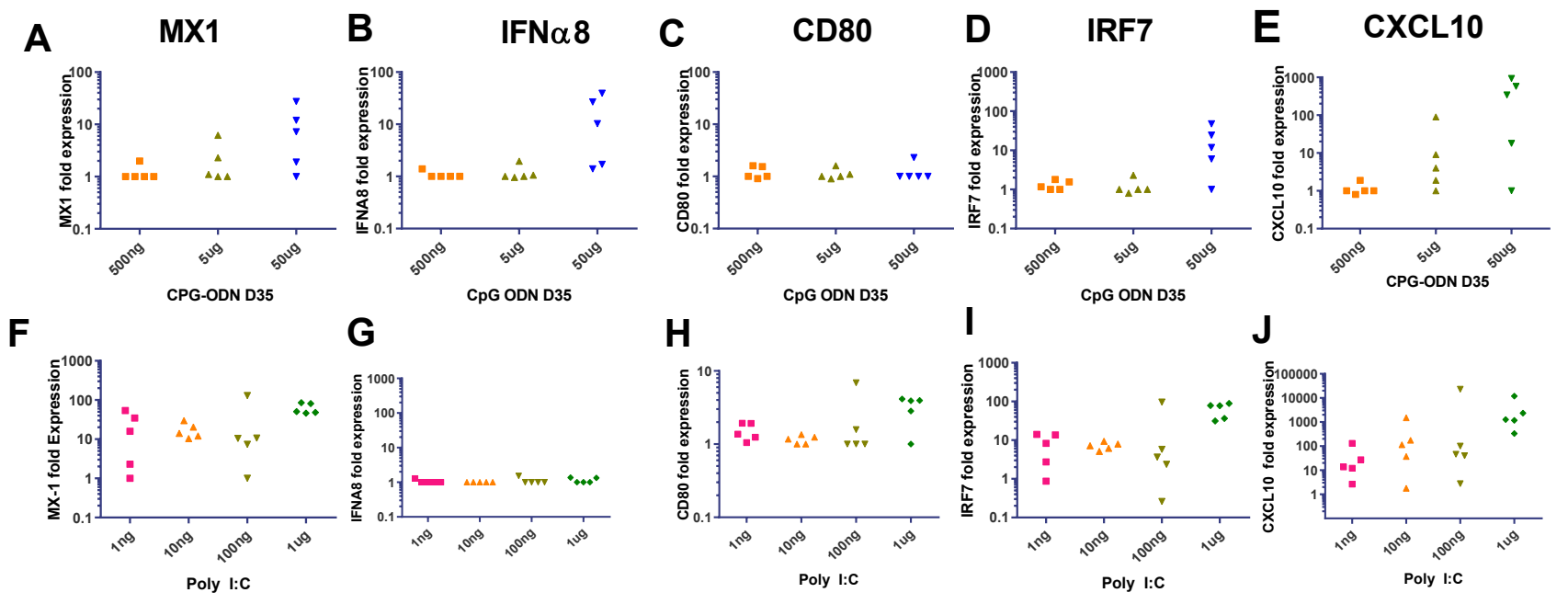

Figure 4 


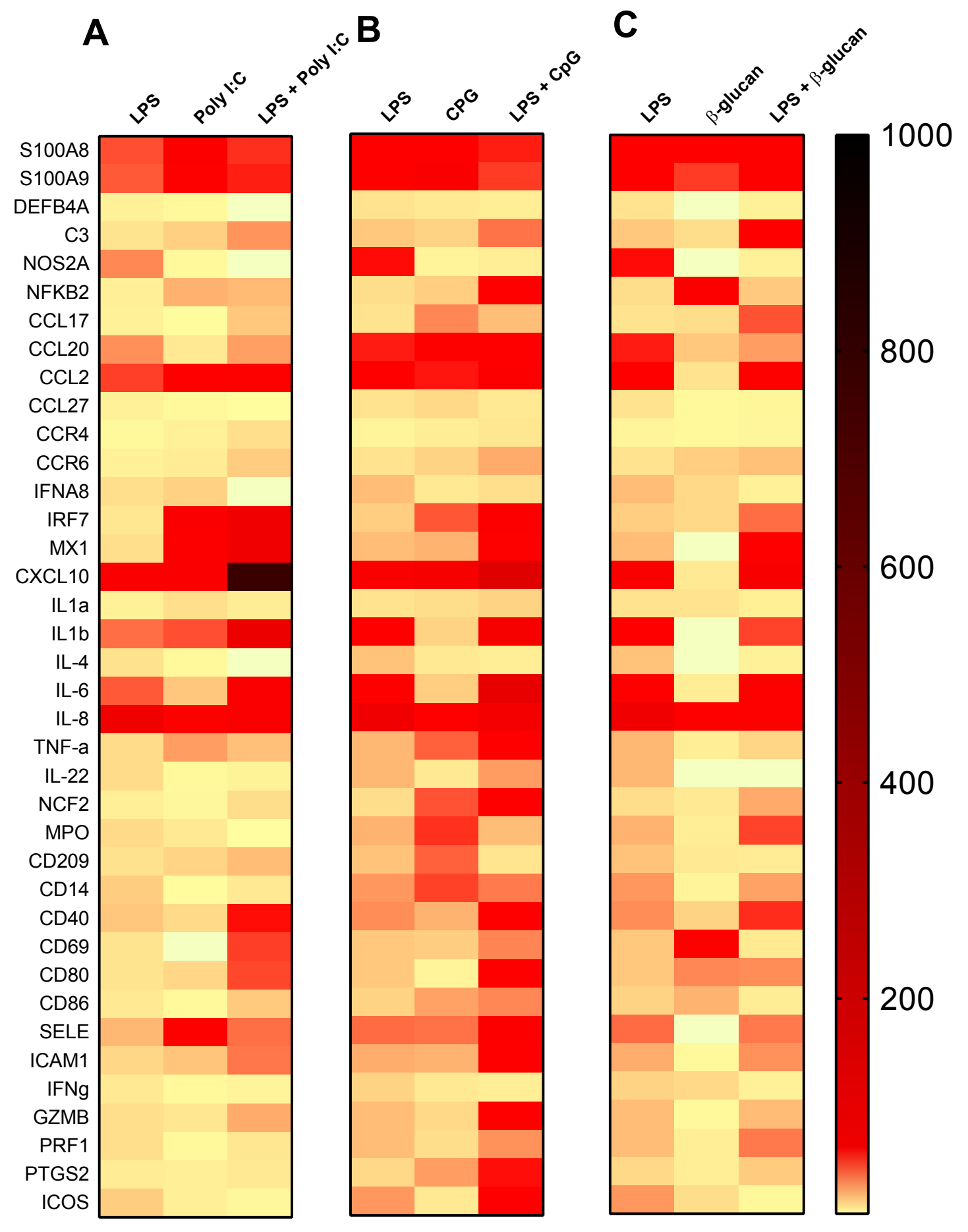

Figure 5 


\section{Endotoxin}

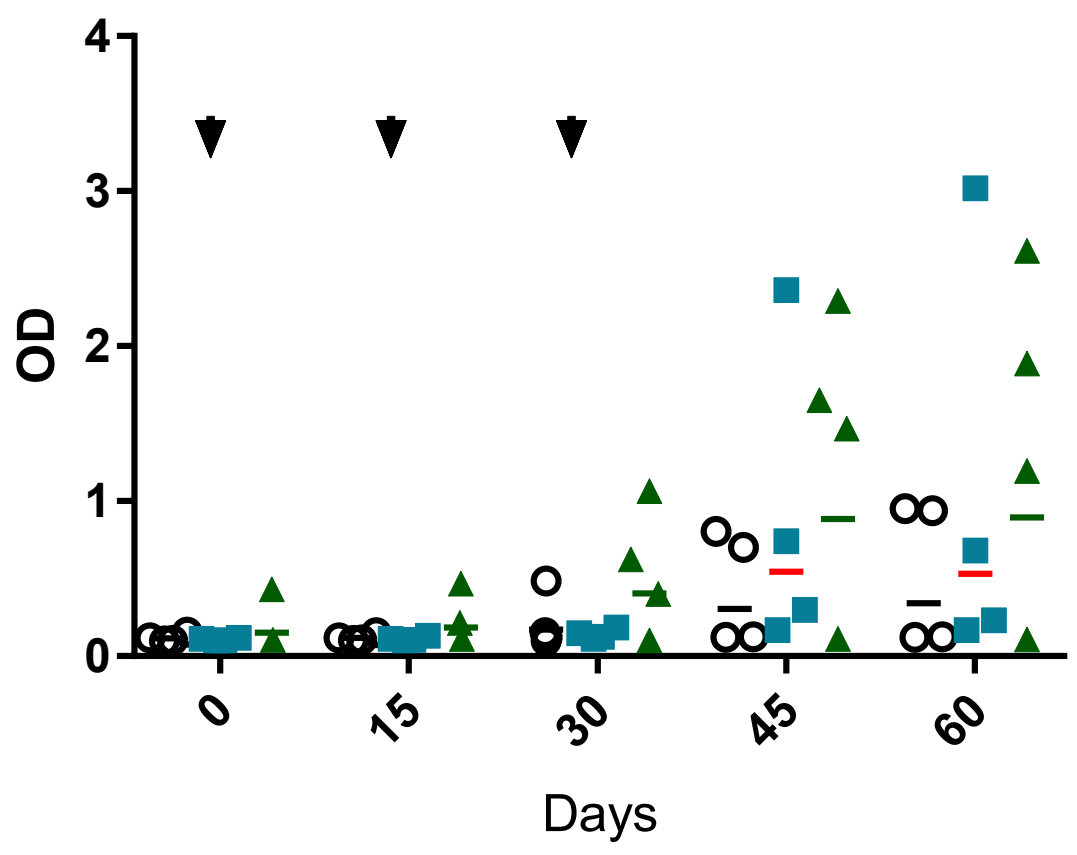

Flagellin

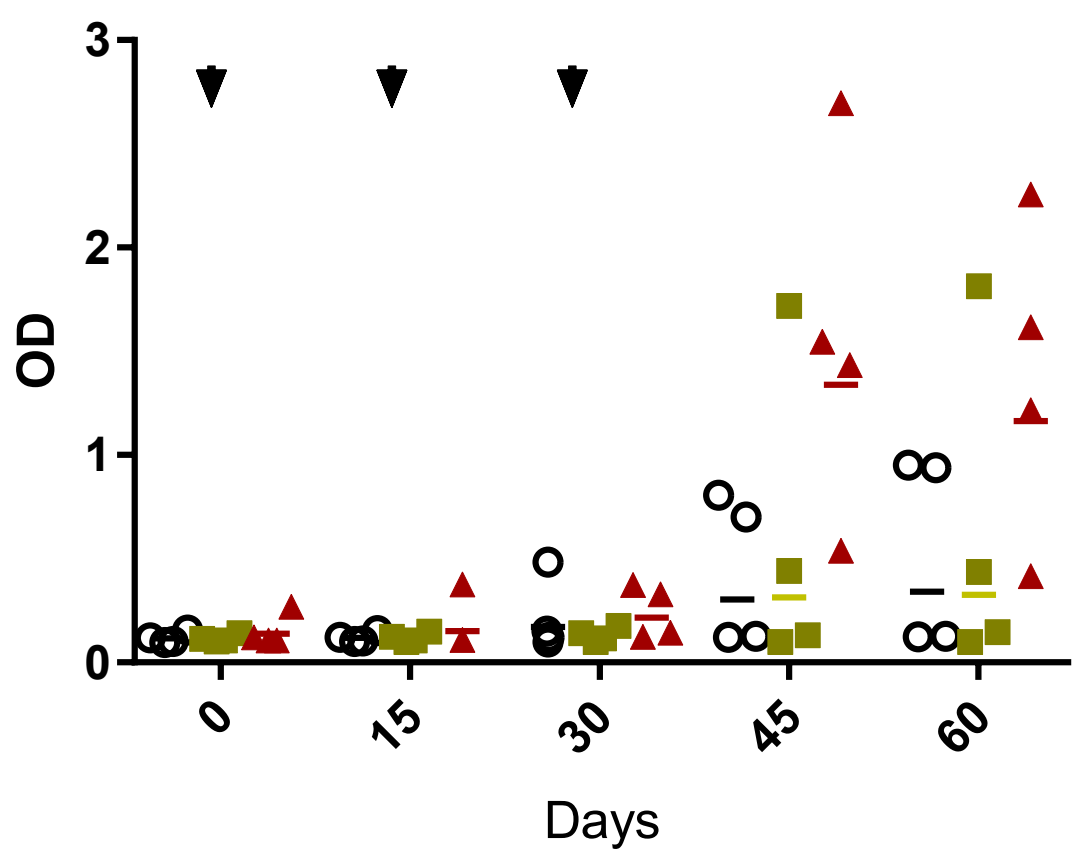

- Elitek

- Elitek + flagellin 1ug

- Elitek + flagellin 10ug
- Elitek

- Elitek + LPS 100pg

\ Elitek + LPS 10ng 